\title{
Older age is associated with a reduced likelihood of ambulance transport to a trauma centre after major trauma in Perth.
}

\begin{abstract}
Objective: To describe the characteristics and outcomes of older adult ( $\geq 65$ years) major trauma patients in comparison with younger adults (16-64 years). To determine whether older age is associated with a reduced likelihood of transport (directly or indirectly) to a major trauma centre and whether this is associated with in-hospital mortality.
\end{abstract}

Methods: A retrospective cohort study of major trauma patients transported to hospital by St John Ambulance paramedics in Perth, Western Australia, between 1st January 2013 and 31st December 2016. Multivariate logistic regression was used to test the relationship between age and trauma centre transport. Multivariate logistic regression analysis using inverse probability of treatment weighting was used to determine if major trauma centre transport was associated with in-hospital mortality in older adults.

Results: 1,625 patients were included; of these $576(35 \%)$ were $\geq 65$ years. In comparison with younger adults, older adults had more falls as their mechanism of injury $(n=358,[62 \%]$ versus $102[10 \%] \mathrm{p}=<0.001)$ and more major head injuries $(\mathrm{n}=472,[82 \%]$ versus $\mathrm{n}=609$ [58\%], $\mathrm{p}=<0.001$ ). Older adults had lower odds (adjusted odds ratio $[A O R] 0.52,95 \%$ confidence interval $[95 \% \mathrm{CI}]$ 0.35-0.78) of major trauma centre transport and this was associated with 1.7 times the likelihood of in-hospital mortality (95\% CI 1.04-2.7).

Conclusions: Older adults who were not transported to the trauma centre had an increased odds of in-hospital mortality. However, older age was associated with a significantly reduced likelihood of trauma centre transport. With the aging population, the development of specific 
prehospital triage criteria to enable the complexities of this higher-risk population to be identified is important.

Key Words: Major Trauma, Older Adults. Prehospital Care, Emergency Medical Services 


\section{Introduction}

Major trauma has traditionally been viewed as a disease of the young, ${ }^{1}$ more specifically, a disease of young males caused by high energy transfer mechanisms of injury. ${ }^{1}$ However, in Australia, an increase in the proportion of patients with major trauma aged $\geq 65$ years has been observed, ${ }^{2}$ an increase that exceeds rates expected from population growth. ${ }^{3}$

Age is a well-described predictor of morbidity and mortality after trauma ${ }^{4,5}$ and patients with major trauma have a significantly lower mortality rate if their care is provided in a major trauma centre (TC). ${ }^{6}$ However, the likelihood of TC transportation has been shown to decrease with age. ${ }^{7}$ The likelihood of non-major TC transportation increases by the age of 60 years ${ }^{8}$ even when TC prehospital triage criteria are met. ${ }^{7,9-11}$

As the population is ageing, ${ }^{12}$ it is important that prehospital care evolves to better understand the needs of older persons following trauma. ${ }^{3}$ Therefore, the objectives of this study were (1) to compare characteristics of older major trauma patients with those of younger patients (2) to compare characteristics of older adult major trauma patients across three age groups. (3) To determine whether older patients are less likely to be transported to the TC than younger patients (directly or indirectly) and (4) to determine the association between non-major TC transport and in-hospital mortality in older adults.

We hypothesised that (i) there would be a difference in the characteristics of major trauma between older and younger patients; (ii) older age would be associated with a reduced likelihood of transport to the TC; and (iii) that non-major TC transport would be associated with in-hospital mortality in older adults, after controlling for known predictors of death in trauma. ${ }^{13}$

\section{Methods}

Study Design 
We conducted a retrospective cohort study of adult ( $\geq 16$ years) major trauma patients with an Injury Severity Score, (ISS) >15 from a blunt, penetrating or thermal mechanism of injury who were transported by St John Ambulance Western Australia (SJA-WA) in metropolitan Perth between $1^{\text {st }}$ January 2013 and $31^{\text {st }}$ of December 2016 . This time period was selected as it was the most recent complete calendar year period with data available. The exposure of interest was age. The primary outcome was transport to the TC and the secondary outcome, in-hospital mortality. We defined older persons as those aged $\geq 65$ years, which is also in accordance with previous definitions of older persons in trauma studies., ${ }^{2,3}$

In keeping with the definition of trauma being 'a body wound produced by sudden physical injury from impact, violence or accident' ${ }^{14}$ we excluded trauma resulting from drowning, hanging or poisoning. This definition is also consistent with previous trauma studies. ${ }^{15,16}$ Patients not transported (i.e. from the scene of the incident) by SJA-WA and patients not transported by road ambulance were excluded from the study. Those with late effects of injury (more than 24-hours post-trauma) and those who had no obtainable initial electronic ambulance transport record were also excluded.

Similar to studies conducted elsewhere, we categorised older adults into three groups for comparison; $65-74,75-84$ and 85 years or older. ${ }^{3}$

\section{Study Setting}

The metropolitan area of Perth, Western Australia (WA) has a population of approximately two million which is $78 \%$ of the state's population. ${ }^{17}$ Over 65 year olds make up $13 \%$ of the state's population, with $79 \%$ of these living in the Perth metropolitan area. ${ }^{18}$ SJA-WA is the sole provider of emergency ambulance services. Each ambulance is staffed with at least one paramedic and a second crew member who is either qualified or in-training. All crews have the capacity to provide advanced-life support, excluding rapid sequence induction. ${ }^{19}$ 
During the study period, major trauma patients in Perth were transported to one of nine hospitals: three tertiary and six secondary hospitals. One of the tertiary hospitals is a Level 1 TC and formally verified by the Royal Australasian College of Surgeons. ${ }^{20,21}$ The other two tertiary hospitals are level 2 TCs (non-major TC) and therefore could provide services and inpatient management for a limited of number of major trauma patients, upon agreement with the TC if the patient's injuries were not considered severe enough to warrant transfer to the TC. ${ }^{20}$ The five secondary hospitals and one private hospital provide definitive care for nonmajor trauma (non-major TC). ${ }^{20}$

For the duration of the study it was recommended by the WA Department of Health, that major trauma patients, defined as any injury that has the potential to cause prolonged disability or death, should be transported directly to the TC. ${ }^{19,22}$ However, if there was an imminent lifethreat, paramedics were permitted to divert to the nearest emergency department for patient stabilisation. ${ }^{19,20}$ It was then recommended that the patient should be prepared for rapid and early inter-hospital transfer to the TC (indirect transport). ${ }^{22}$

\section{Data Sources}

There are four hospitals that contribute data to the State Trauma Registry using the same data definitions. These hospitals are the three tertiary hospitals, including the TC and one of the secondary hospitals. Patients are also included in the registry if they are transferred to one of these facilities after initial treatment at another hospital that did not provide data to the registry. ${ }^{23}$

We identified patients in the State Trauma Registry if their ISS was $>15$, their mode of arrival was recorded as 'ambulance' and the location of injury occurrence was described as 'metropolitan'. We then extracted demographic details, injury mechanism, injury 
characteristics, length of hospital stay and date of death. We linked these data with the ambulance transport record from the SJA-WA database using either deterministic or probabilistic matching (FRIL ver.2.1.5, Emory University and Centers for Disease Control and Prevention, Atlanta, Georgia, U.S.). Date of birth, first and last names and residential address were used as key identifiers to create a score indicating likelihood of a correct link between the databases. These scores were then manually checked if they were close to a predetermined cutoff value. If the key identifiers were missing in the SJA-WA database then linkage failure occurred. The SJA-WA database contains data from the electronic patient care record (ePCR), completed for each case by paramedics, together with data from the computer-aided dispatch system. From this database, we extracted the patient transport destination and prehospital observations.

A severity level for each injury was measured according to the Abbreviated Injury Scale (AIS) ranging from 6 (fatal) to 1 (minor). We used AIS codes to identify whether a patient sustained a major injury in the six ISS body regions (head/neck, face, chest, abdomen, extremities and external). We defined major injury as an injury with AIS $\geq 3$. The cut-off values for the Triage Revised Trauma Score informed categorisation of the physiological parameters (Glasgow Coma Scale Score (GCS), systolic blood pressure (SBP) and respiratory rate) and these were determined so that there would be at least 10 patients per category to reduce bias and improve precision. $^{24}$

\section{Statistical Analysis}

To describe the cohort, median and inter-quartile range (IQR) were used for continuous variables and counts and percentages for categorical variables. Differences between the age groups were assessed using the Kruskal-Wallis test for continuous variables and Pearson chisquare for categorical variables. Binary logistic regression was used to determine whether age 
$\geq 65$ years was associated with a likelihood of transport to the TC whilst adjusting for mechanism of injury, ISS, first prehospital GCS, major injuries in head, chest, abdomen and extremities and sex. Unadjusted odds ratios (OR), adjusted odds ratios (AOR) and their 95\% confidence intervals $(\mathrm{CI})$ were calculated. A $p$-value $<0.05$ was regarded as statistically significant. Potential interactions were tested and the presence of effect modification was deemed significant if a $p$-value of the interaction term was less than 0.05 . The HosmerLemeshow $\chi^{2}$ test was used to assess goodness of fit of the model.

We used logistic regression to estimate the odds ratio (OR) and their 95\% confidence intervals (CI) for in-hospital mortality to compare older adults ( $\geq 65$ years) transported to the TC (directly or indirectly) with non-major TC transport. Adjustment was made for the following predictors: ISS $\geq 25$, age, the presence of a major head injury and the incidence of a SBP $<90 \mathrm{mmHg}$, GCS $\leq 8$ and respiratory rate $<9$ or $>29$ at any time prehospital. The logistic regression model was applied with inverse probability of treatment weighting (IPTW) using the propensity scores. ${ }^{25}$ Propensity scores were computed with binary logistic regression including the same predictors as the main model except the variable indicating a destination (transport to TC or non-major TC), which was used as the dependent variable. Assessment of the imbalance of predictors was undertaken by comparing the standardised mean difference (SMD) before and after IPTW.

With the sample size in this study we had $90 \%$ power to detect odds ratios for trauma centre transport of $<0.67$ and $>1.59$ for older patients $(\geq 65$ years) compared to younger patients $(<65$ years) at the $5 \%$ significance level assuming that $80 \%$ of younger adult patients receive trauma centre transport.

Data analysis was performed with IBM Statistical Package for Social Sciences (SPSS) Version 24.0 (IBM, Armonk, NY, USA).

\section{Ethics Approval}


Ethical approval was obtained from the Curtin University Human Research Ethics Committee (HR 128/2013). Ethics approval for access to the State Trauma Registry data was obtained from the Royal Perth Hospital Human Research Ethics Committee (PRN 464). Approval to access the SJA-WA data was obtained from the St John Ambulance Research Governance Committee.

\section{Results}

We identified 1,664 major trauma patients with an Injury Severity Score (ISS) $>15$ from a blunt, penetrating or thermal mechanism of injury who were transported by St John Ambulance WA (SJA-WA) in metropolitan Perth during the 4 year study period. Of these 1,664 records; we could not obtain the initial ambulance transport record for 34 cases. Three cases could not be linked, possibly due to inaccurate identifiers or incorrect recording of the mode of transport in the registry and two cases were duplicated in the registry (Figure 1).

Included in the study were 1,625 major trauma patients. Of these $576(35 \%)$ were $\geq 65$ years of age. In the younger adult group (16-64 years), the median age was 36 (IQR 25-50) and 851 (81\%) were male; whereas in the older adult group $(\geq 65)$ the median age was 80 years (IQR 74-87) and 307 (53\%) were male (Table 1).

Overall, the most common mechanism of injury was a fall from standing ( $\mathrm{n}=460,28 \%)$ with $12 \%$ more patients injured by this mechanism than the second most common mechanism, motor vehicle crashes $(n=259,16 \%)$. For the younger adult group motorbike crashes were the most common mechanism of injury $(n=212,20 \%)$; whereas falls from standing were the most common in the older adult group $(n=358,62 \%)$. (Table 1). Other differences included the location where the injury occurred; in the younger adult group, this was most commonly on a street or highway $(n=546,52 \%)$ whereas the older adult group injuries most commonly 
occurred at home $(n=295,51 \%)$. The presence of major head injuries was also greater in older adults $(n=472,[82 \%]$ versus $n=609[58 \%], p=<0.001)$.

As age increased the proportion of female patients increased and in the oldest age group $(\geq 85$ years) females accounted for 55\% (n=108) compared with $36 \%(n=57)$ in those aged $65-74$ years (Table 2). A median ISS of 21 (IQR 17-26) in the oldest age group ( $\geq 85$ years) was significantly lower than the ISS of 25 (IQR 17-29) for 65-74 group ( $p=0.004)$.

Younger adults had the lowest percentage of deaths in-hospital ( $n=169$ [15\%] versus, $n=170$ [30\%] $p<0.001$ ) (Table 1). The majority of patients in the younger adult group were taken directly to the TC ( $\mathrm{n}=578,55 \%)$ whereas the majority of patients in the older adult group were non-major TC transports $(\mathrm{n}=232[40 \%], p<0.001)$ (Table 1). In the oldest group ( $\geq 85$ years) $50 \%(n=98)$ were non-major TC transports compared to $32 \%(n=51)$ of those aged $65-74$ years and $38 \%(n=83)$ of those aged $75-85$ years (Table 2$)$.

A multivariate logistic regression model was applied with transport to the $\mathrm{TC}$ as an outcome, adjusting for age, sex, mechanisms of injury, prehospital GCS, ISS, existence of major head, chest, abdominal and/or extremity injuries. This model showed a reduction in the odds of TC transport with increasing age (Table 3). Compared to younger adults, those aged 65-74 years had a $48 \%$ reduction in the odds of being transported to the TC (AOR $0.5295 \%$ CI $0.35-0.78$ ) and those aged $\geq 85$ years had a $63 \%$ reduction (AOR $0.3795 \%$ CI $0.24-0.55$ ) (Table 3 ). Overall, a fall from standing resulted in more than 53\% reduced odds of TC transport (AOR $0.4795 \% 0.33-0.67$ ). Positive predictors of TC transport included motor vehicle crash (AOR $2.595 \%$ CI 1.6-4.0) and male gender (AOR 1.4 95\% CI 1.1-1.8). There was no evidence of effect modification between the age variable and any other variable (all interactions $p>0.05$ ). There was little evidence of poor model fit (Hosmer-Lemeshow $\left.\chi^{2}=6.04, p=0.64\right)$. 
After weighting, the potential imbalance between the transport groups was mostly eliminated as shown by the standardised mean difference (Appendix 1) except for age. The IPTW multivariate logistic regression analysis showed that in patients $\geq 65$ years non-major TC transport was associated with 1.7 times increased likelihood of in-hospital mortality (CI 95\% 1.04-2.7) (Table 4). Similarly, ISS $\geq 25$, age, GCS $\leq 8$ or a respiratory rate $\leq 9$ or $>29$ per min any time prehospital were also significantly associated with increased likelihood of in-hospital mortality.

\section{Discussion}

This study compared the characteristics of major trauma in younger and older patients. Consistent with previous studies of major trauma in older adults, we found that falls from standing were the most common mechanism of injury ${ }^{1-3}$ and as age increased the proportion of falls increased. ${ }^{3}$ Similar to a study undertaken in Victoria, we found that with each increasing age group the proportion of patients who received definitive care at a non-major TC increased. ${ }^{3}$ Furthermore, we identified an in-hospital mortality benefit in older adults transported to the TC, which is consistent with previous research of adult major trauma patients ${ }^{6}$ and a study of minimally injured (ISS $<9)$ older adults. ${ }^{26}$

We identified that the odds of transport to the TC in older adults was between $48 \%$ and $63 \%$ lower than their younger counterparts. This trend is consistent with previous research. ${ }^{7,10,27} \mathrm{~A}$ study from Victoria which examined age and prehospital triage destination, reported that for older patients the odds of transportation to a major trauma service were between $23.7 \%$ and $41.1 \%$ lower than for patients aged $16-25$ years. ${ }^{10}$ A reduction in the likelihood of TC transport of $52 \%$ for those $\geq 65$ years (AOR $0.4895 \%$ CI $0.30-0.76$ ) was also reported in Baltimore, USA, where trauma patients were defined as those being declared priority 1 status by emergency medical personnel. ${ }^{27}$ Similarly, in urban New South Wales, age $>70$ years was 
associated with a $62 \%$ reduction (AOR $0.3895 \%$ CI $0.29-0.49$ ) in those meeting a prehospital trauma triage protocol, which recommends TC transport. $^{7}$

The reasons why older adults have a reduced odds of TC transport is likely to be due to multiple factors. Older adults are known to have the ability to sustain major trauma as a result of lowvelocity mechanisms such as falls ${ }^{8}$ and falls have also been found to be associated with a decreased likelihood of TC transport. ${ }^{7}, 11,28$ Seriously injured older adults can appear deceptively uninjured, often failing to display overt physiological derangement. ${ }^{29}$ For example, it has been found that for the equivalent severity of intracranial injury, the presenting GCS is higher in older adults than their younger counterparts, suggesting that the severity of major head injuries may not initially be apparent. ${ }^{30}$ Furthermore, older adults often have significant comorbidities, polypharmacy, anticoagulation therapy and physiologic changes that can alter their response to injury or occult hypoperfusion which require high levels of suspicion to recognise. ${ }^{8}$

It has been suggested that a lack of paramedic training about trauma in older adults contribute to older persons not being transported to TCs. ${ }^{27}$ Conversely, it is possible that paramedics do recognise the severity of the patient's condition and consider active trauma care as futile due to age, injury severity, existing comorbidities and likely prognosis and therefore, chose not to transport older patients to the TC. This may also account for older patients not being subsequently transferred to the TC after initial stabilisation at another hospital with the assessment that transfer to the TC is inappropriate for that patient. ${ }^{3,10}$ It has also been suggested that older adults may prefer to attend non-major TCs due to their to prior history at local hospitals. $^{3}$

Standard adult triage criteria have been found to be too restrictive in identifying the need for TC care in older adults. ${ }^{31}$ However, the adoption of specific field triage criteria have been 
shown to significantly improve the detection of older adults requiring this specialised care. ${ }^{31}$ At present, no specific field triage criteria for the management of older adult trauma patients is in use by SJA-WA paramedics. As we have previously highlighted, the incidence of trauma in metropolitan Perth is the highest in those $\geq 85$ years ${ }^{32}$ with older adults comprising $35 \%$ of the major trauma patients in our current study. It is therefore important that we develop specific prehospital triage criteria to enable the identification of these higher-risk patients in whom TC transport would be beneficial.

\section{Limitations}

As with any observational study design there may have been unknown confounders that influenced associations seen in the multivariate analysis. Patients who died at the scene or exclusively attended a hospital that did not provide data to the WA State Trauma Registry were not captured by the study. Therefore, this study is not population-based. However, this is more likely to have resulted in an underestimation of the reduction in the likelihood of transport direct to the designated TC in older adults.

\section{Conclusion}

Older age was associated with a significantly reduced likelihood of TC transport. The reasons for this are likely to be complex. However, as the population is aging, the development of specific prehospital triage criteria to enable the complexities of this higher-risk patient population to be identified is important.

\section{Conflict of Interests}

Paul Bailey is the Clinical Services Director for St John Ambulance Western Australia (SJAWA) and Judith Finn receives partial salary support from SJA-WA. Elizabeth Brown is a SJAWA paramedic and $\mathrm{PhD}$ candidate and the recipient of a Scholarship funded by a National 
Health and Medical Research Council (NHMRC) Prehospital Emergency Care Centre for Research Excellence grant (1116453).

\section{Acknowledgments}

The authors are grateful for the assistance of Maxine Burrell, State Trauma Programme Manager and thank SJA-WA for their support of our study.

\section{References.}

1. Kehoe A, Smith JE, Edwards A, Yates D, Lecky F. The changing face of major trauma in the UK. Emerg Med J. 2015;32(12):911-5.

2. Dinh MM, Roncal S, Byrne CM, Petchell J. Growing trend in older patients with severe injuries: mortality and mechanisms of injury between 1991 and 2010 at an inner city major trauma centre. ANZ J Surg. 2013;83(1-2):65-9.

3. Beck B, Cameron P, Lowthian J, Fitzgerald M, Judson R, Gabbe BJ. Major trauma in older persons. BJS Open. 2018;2(5):310-318.

4. Shifflette VK, Lorenzo M, Mangram AJ, Truitt MS, Amos JD, Dunn EL. Should age be a factor to change from a level II to a level I trauma activation? J Trauma. 2010;69(1):88-92.

5. Fatovich DM, Jacobs IG, Langford SA, Phillips M. The effect of age, severity, and mechanism of injury on risk of death from major trauma in Western Australia. J Trauma Acute Care Surg. 2013;74(2):647-51.

6. MacKenzie EJ, Rivara FP, Jurkovich GJ, et al A National Evaluation of the Effect of Trauma-Center Care on Mortality. N Engl J Med. 2006;354(4):366-78.

7. Fitzharris M, Stevenson M, Middleton P, Sinclair G. Adherence with the pre-hospital triage protocol in the transport of injured patients in an urban setting. Injury. 2012;43(9):1368-76.

8. Nakamura Y, Daya M, Bulger EM, et al. Evaluating age in the field triage of injured persons. Ann Emerg Med. 2012;60(3):335-45.

9. van Rein EAJ, van der Sluijs R, Raaijmaakers AMR, Leenen LPH, van Heijl M. Compliance to prehospital trauma triage protocols worldwide: A systematic review. Injury. 2018;49(8):1373-80.

10. Cox S, Morrison C, Cameron P, Smith K. Advancing age and trauma: Triage destination compliance and mortality in Victoria, Australia. Injury. 2014;45(9):1312

11. Doumouras AG, Haas B, Gomez D, De Mestral C, Boyes DM, Morrison LJ, Craig AM, Nathens AB. The Impact of Distance on Triage to Trauma Center Care in an Urban Trauma System. Prehosp Emerg Care, 2012;16(4);456-462.

12. Australian Bureau of Statistics. 2071.0 - Census of Population and Housing: Reflecting Australia - Stories from the Census, 2016 [Updated $23^{\text {rd }}$ October 2017. Cited 25 $5^{\text {th }}$ August 2018] http://www.abs.gov.au/ausstats/abs@.nsf/Lookup/by\%20Subject/2071.0 2016 Main \%20Features Ageing\%20Population 14 (Acessed 12 ${ }^{\text {th }}$ September 2018).

13. Strnad M, Lesjak VB, Vujanovic V, Pelcl T, Krizmaric M. Predictors of mortality and prehospital monitoring limitations in blunt trauma patients. Biomed Res Int. 2015;2015:983409. 
14. Department of Health. Healthy WA - Health Information for Western Australians.Trauma. [Updated $30^{\text {th }}$ March 2018. Cited 25 $5^{\text {th }}$ August 2018] http://healthywa.wa.gov.au/Articles/S_T/Trauma (Acessed $25^{\text {th }}$ August 2018).

15. McCoy CE, Menchine M, Sampson S, Anderson C, Kahn C. Emergency Medical Services Out-of-Hospital Scene and Transport Times and Their Association With Mortality in Trauma Patients Presenting to an Urban Level I Trauma Center. Ann Emerg Med. 2013;61(2):167-74.

16. Beck B, Bray JE, Cameron P, et al. Predicting outcomes in traumatic out-of-hospital cardiac arrest: the relevance of Utstein factors. Emerg Med J. 2017; 34(12), 786-792.

17. Australian Bureau of Statistics. Australian Demographic Statistics. 2016 Census. [Updated 26 ${ }^{\text {th }}$ June 2017 Cited 20 ${ }^{\text {th }}$ August 2018] http://www.abs.gov.au/AUSSTATS/abs@.nsf/allprimarymainfeatures/CFE97018EC4 9EB38CA2580F2000BEBB4. (Accessed 25th August 2018).

18. Australian Bureau of Statistics. 3235.0 Population by Age and Sex, Regions of Australia, 2015. [Updated $18^{\text {th }}$ August 2016 Cited $14^{\text {th }}$ September 2018] http://www.abs.gov.au/ausstats/abs@.nsf/mf/3235.0 (Accessed 14th September 2018).

19. St John Ambulance Western Australia Ltd. Clinical Practice Guidelines For Ambulance Care In Western Australia - Paramedic Industrial Paramedic Ambulance Officer Ambulance Transport Officer - Version 31. [Clinical Practice Guidelines]. 2017.

20. Towler S. Trauma System and Services - Report of the Trauma Working Group. Western Australia: Delivering a Healthy WA, 2007. [Updated. $25^{\text {th }}$ July 2017 Cited $20^{\text {th }}$ August 2018] http://www.health.wa.gov.au/trauma_system_and_services/home/about.cfm (Accessed 25 ${ }^{\text {th }}$ August 2018).

21. Government of Western Australia East Metropolitan Health Service. Royal Perth Hospital [Updated 22 ${ }^{\text {nd }}$ March 2018. Cited $16^{\text {th }}$ November 2018]: https://rph.health.wa.gov.au/Our-services/Trauma-Service (Accessed $16^{\text {th }}$ Novemebr 2018).

22. Government of Western Australia -Department of Health. Guiding Principles for Major Trauma Inter Hospital Transfer. [Updated $31^{\text {st }}$ July 2013. Cited $20^{\text {th }}$ August 2018] www.health.wa.gov.au/trauma_system_and_services/home/ (Accessed 25th August 2018 )

23. Western Australian Department of Health. WA State Trauma Registry. [Updated $30^{\text {th }}$ March 2018 Cited 20 ${ }^{\text {th }}$ August 2018] https://ww2.health.wa.gov.au/Articles/U_Z/WA-State-Trauma-Registry (Accessed $25^{\text {th }}$ August 2018).

24. Vittinghoff E, McCulloch CE. Relaxing the rule of ten events per variable in logistic and Cox regression. Am J Epidemiol. 2007;165(6):710-8.

25. Rosenbaum PR. Model-Based Direct Adjustment. J Am Stat Assoc. 1987;82(398):38794.

26. Goodmanson NW, Rosengart MR, Barnato AE, Sperry JL, Peitzman AB, Marshall GT. Defining geriatric trauma: when does age make a difference? Surgery. 2012;152(4):668-74.

27. Chang DC, Bass RR, Cornwell EE, Mackenzie EJ. Undertriage of elderly trauma patients to state-designated trauma centers. Arch Surg. 2008;143(8):776-81.

28. Staudenmayer KL, Hsia RY, Mann NC, Spain DA, Newgard CD. Triage of elderly trauma patients: a population-based perspective. J Am Coll Surg. 2013;217(4):569-76. 
29. Fatovich DM, Burrell M, Jacobs IG. Major trauma deaths at Perth secondary hospitals. Emerg Med Australas. 2011;23(6):754-60.

30. Kehoe A, Smith JE, Bouamra O, Edwards A, Yates D, Lecky F. Older patients with traumatic brain injury present with a higher GCS score than younger patients for a given severity of injury. Emerg Med J. 2016;33(6):381-5.

31. Ichwan B, Darbha S, Shah MN, et al. Geriatric-specific triage criteria are more sensitive than standard adult criteria in identifying need for trauma center care in injured older adults. Ann Emerg Med. 2015;65(1):92-100.

32. Brown E, Williams TA, Tohira H, Bailey P, Finn J. Epidemiology of trauma patients attended by ambulance paramedics in Perth, Western Australia. Emerg Med Australas. 2018;30(6):827-833.

Reference Table 1 and Table 2.

1. Hemmila MR, Cain-Nielsen AH, Wahl WL, Vander Kolk WE, Jakubus JL, Mikhail JN, Birkmeyer NJ. Regional collaborative quality improvement for trauma reduces complications and costs. Journal of Trauma and Acute Care Surgery. 2015;78(1):7887.

Reference Figure 1.

1. Brown E, Tohira H, Bailey P, Fatovich D, Pereira G, Finn J. Longer prehospital time was not associated with mortality in major trauma. A retrospective cohort study. Prehosp Emerg Care. Forthcoming 2018. 
Figure One. Flowchart of included and excluded patients $\geq 16$ years of age with major trauma, defined as an Injury Severity Score of $>15$ from a blunt, penetrating or thermal mechanism of injury and transported by St John Ambulance WA (SJA-WA) in the Perth metropolitan area, WA either directly or indirectly to one of four hospitals who provided data to the WA State Trauma Registry between $1^{\text {st }}$ January 2013 and $31^{\text {st }}$ December $2016 .^{1}$

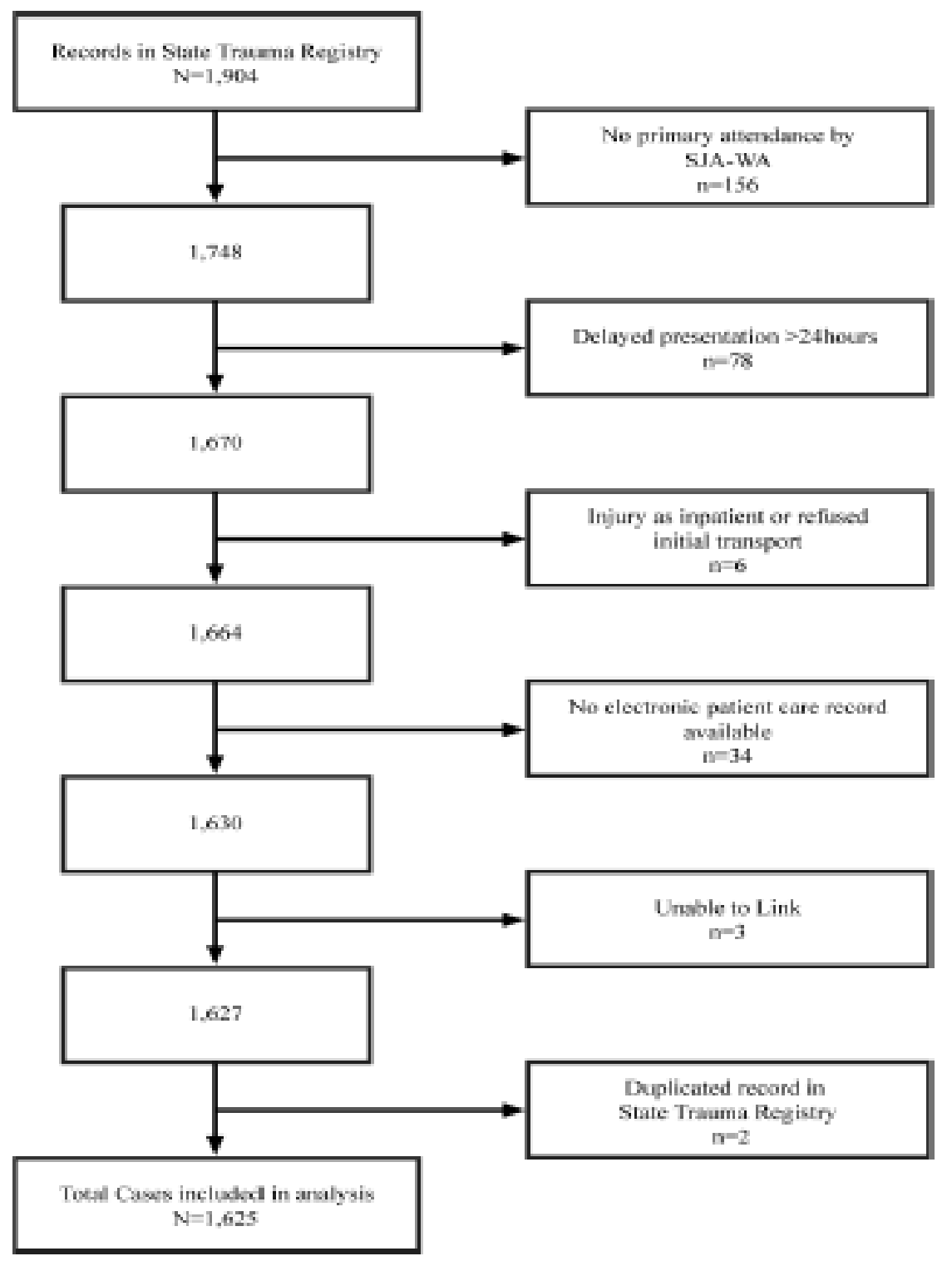


Table 1. Comparison of demographic, event and injury characteristics between adults with major trauma (ISS >15) aged 16-64 and $\geq 65$.

\begin{tabular}{|c|c|c|c|c|}
\hline & $\begin{array}{c}\text { Overall } \\
N=1,625\end{array}$ & $\begin{array}{c}\text { Age 16-64 years } \\
\quad N=1,049\end{array}$ & $\begin{array}{c}\text { Age } \geq 65 \text { years } \\
N=576\end{array}$ & $p$ value \\
\hline \multicolumn{5}{|l|}{ Sex } \\
\hline Male & $1158(71)$ & $851(81)$ & $307(53)$ & \\
\hline Female & $467(29)$ & $198(19)$ & $269(47)$ & $<0.001$ \\
\hline Age & $51(30-75)$ & $36(25-50)$ & $80(74-87)$ & $<0.001$ \\
\hline \multicolumn{5}{|l|}{ Outcome II } \\
\hline In-Hospital Mortality & $339(21)$ & $169(15)$ & $170(30)$ & $<0.001$ \\
\hline Death in Emergency Department & $105(6.5)$ & $76(7.2)$ & $29(5.0)$ & 0.083 \\
\hline \multicolumn{4}{|l|}{ LOS median (IQR) } & 0.167 \\
\hline Any Serious Complications † & $407(25)$ & $268(25)$ & $139(24)$ & 0.529 \\
\hline Prehospital CPR & $102(6.3)$ & $87(8.3)$ & $15(2.6)$ & $<0.001$ \\
\hline Injury Severity Score median (IQR) & $22(17-27)$ & $24(17-29)$ & $22(17-26)$ & $<0.001$ \\
\hline Major Head Injury & $1081(66)$ & $609(58)$ & $472(82)$ & $<0.001$ \\
\hline Major Chest Injury & $605(37)$ & $475(45)$ & $130(23)$ & $<0.001$ \\
\hline Major Abdominal Injury & $243(15)$ & $208(20)$ & $35(6.1)$ & $<0.001$ \\
\hline Major External Injury & $43(2)$ & $32(3.1)$ & $11(1.9)$ & 0.171 \\
\hline Major Extremity Injury & $281(17)$ & $223(21)$ & $58(10)$ & $<0.001$ \\
\hline \multicolumn{5}{|l|}{ Mechanism of Injury } \\
\hline Fall from standing & $460(28)$ & $102(10)$ & $358(62)$ & \\
\hline Fall from height & $222(14)$ & $141(13)$ & $81(14)$ & \\
\hline Motor Vehicle Crash & $259(16)$ & $196(19)$ & $63(11)$ & \\
\hline Motor Bike Crash & 217 (13) & $212(20)$ & $5(1.0)$ & $<0.001$ \\
\hline Pedal Cyclist & $69(4.0)$ & $51(5.0)$ & $18(3.0)$ & \\
\hline Pedestrian & $106(7.0)$ & $74(7.0)$ & $32(6.0)$ & \\
\hline Violence & $159(10)$ & $151(14)$ & $8(1.0)$ & \\
\hline Other $\neq$ & $133(8.0)$ & $122(12)$ & $11(2.0)$ & \\
\hline \multicolumn{5}{|l|}{ Location of Injury Occurrence } \\
\hline Home & $513(32)$ & $218(21)$ & $295(51)$ & \\
\hline Residential Institution & $95(6)$ & $4(1.0)$ & $91(16)$ & \\
\hline Street or Highway & $670(41)$ & $546(52)$ & $124(21)$ & $<0.001$ \\
\hline Public Area & $117(7)$ & $89(8.0)$ & $28(5)$ & \\
\hline Other & $230(14)$ & $192(18)$ & $38(7)$ & \\
\hline \multicolumn{5}{|l|}{ Response Priority } \\
\hline Priority 1 & $1290(79)$ & $932(89)$ & $358(62)$ & \\
\hline Priority 2 & $304(19)$ & $112(10.5)$ & $192(33)$ & $<0.001$ \\
\hline Priority 3 & $31(2)$ & $5(0.5)$ & $26(5)$ & \\
\hline \multicolumn{5}{|l|}{ Transport Priority $\S$} \\
\hline Priority 1 & 759 (47) & $592(56)$ & $167(29)$ & \\
\hline Priority 2 & $537(33)$ & $340(32)$ & $197(34)$ & $<0.001$ \\
\hline Priority 3 and lower & $326(20)$ & $114(11)$ & $212(37)$ & \\
\hline \multicolumn{5}{|l|}{ Hospital Destination } \\
\hline Direct to Major Trauma Centre & $766(47)$ & $578(55)$ & $188(33)$ & \\
\hline
\end{tabular}




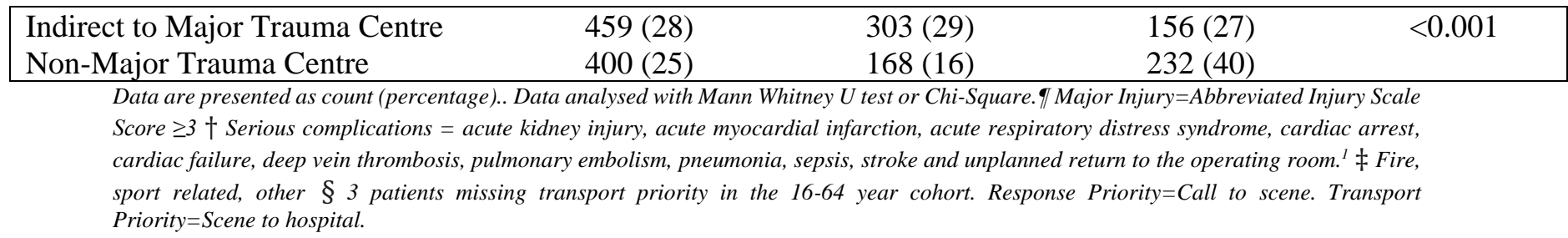

Table 2. Comparison of demographic, event and injury characteristics between older adults with major trauma (ISS>15) stratified by age group.

\begin{tabular}{|c|c|c|c|c|}
\hline & $\begin{array}{c}\text { Age } \\
\text { 65-74 years } \\
(\mathrm{N}=159)\end{array}$ & $\begin{array}{c}\text { Age } \\
\text { 75-84 years } \\
(\mathrm{N}=219)\end{array}$ & $\begin{array}{c}\text { Age } \\
\geq 85 \text { years } \\
(\mathrm{N}=198)\end{array}$ & $p$ value \\
\hline \multicolumn{5}{|l|}{ Sex } \\
\hline Male & $102(64)$ & $115(52)$ & $90(45)$ & 0.002 \\
\hline Female & $57(36)$ & $104(48)$ & $108(55)$ & \\
\hline \multicolumn{5}{|l|}{ Outcome } \\
\hline In-Hospital Mortality & $38(24)$ & $63(29)$ & $69(35)$ & 0.075 \\
\hline Death in Emergency & $8(5)$ & $12(6)$ & $9(5)$ & 0.909 \\
\hline \multicolumn{5}{|l|}{ Department } \\
\hline \multicolumn{4}{|l|}{ LOS median (IQR) } & 0.013 \\
\hline \multicolumn{5}{|l|}{ Injury Characteristics II } \\
\hline Any Serious Complications † & $42(26)$ & $51(23)$ & $46(23)$ & 0.731 \\
\hline $\begin{array}{l}\text { Injury Severity Score median } \\
\text { (IQR) }\end{array}$ & $25(17-29)$ & $24(17-26)$ & $21(17-26)$ & 0.004 \\
\hline Major Head Injury & $119(75)$ & $179(82)$ & $174(88)$ & 0.006 \\
\hline Major Chest Injury & $55(35)$ & $50(23)$ & $25(13)$ & $<0.001$ \\
\hline Major Abdominal Injury & $12(7.5)$ & $17(7.8)$ & $6(3.0)$ & 0.086 \\
\hline Major Extremity Injury & $17(11)$ & $23(10)$ & $18(10)$ & 0.851 \\
\hline \multicolumn{5}{|l|}{ Mechanism of Injury } \\
\hline Fall from standing & $61(38)$ & $136(62)$ & $161(81)$ & \\
\hline Fall from height & $31(20)$ & $32(15)$ & $18(9.0)$ & $<0.001$ \\
\hline Motor Vehicle Crash $\neq$ & $29(18)$ & $29(13)$ & $10(5.0)$ & \\
\hline Pedestrian & $8(5.0)$ & $16(7.0)$ & $8(4.0)$ & \\
\hline Other § & $30(19)$ & $6(3.0)$ & $1(1.0)$ & \\
\hline \multicolumn{5}{|l|}{ Location of Injury Occurrence } \\
\hline Home & $74(47)$ & $112(51)$ & $109(55)$ & \\
\hline Residential Institution & $3(2.0)$ & $28(13)$ & $60(30)$ & $<0.001$ \\
\hline Street or Highway & $56(35)$ & $48(22)$ & $20(10)$ & \\
\hline Public Area & $8(5.0)$ & $15(7.0)$ & $5(3.0)$ & \\
\hline Other & $18(11)$ & $16(7.0)$ & $4(2.0)$ & \\
\hline \multicolumn{5}{|l|}{ Response Priority } \\
\hline Priority 1 & $121(76)$ & $138(63)$ & $99(50)$ & \\
\hline Priority 2 & $34(21)$ & $70(32)$ & $88(44)$ & $<0.001$ \\
\hline Priority 3 & $4(3.0)$ & $11(5.0)$ & $11(6.0)$ & \\
\hline \multicolumn{5}{|l|}{ Transport Priority } \\
\hline Priority 1 & $61(38)$ & $69(31)$ & $37(19)$ & \\
\hline Priority 2 & $67(42)$ & $80(37)$ & $50(25)$ & $<0.001$ \\
\hline $\begin{array}{l}\text { Priority } 3 \text { and lower } \\
\text { Hospital Destination }\end{array}$ & $31(20)$ & $70(32)$ & $111(56)$ & \\
\hline
\end{tabular}




\begin{tabular}{|llll|}
\hline Direct to Trauma Centre & $53(33)$ & $73(33)$ & $62(31)$ \\
Indirect to Trauma Centre & $55(35)$ & $63(29)$ & $38(19)$ \\
Non-Major Trauma Centre & $51(32)$ & $83(38)$ & $98(50)$ \\
\hline
\end{tabular}

Data are presented as count (percentage). Data analysed with Kruskal-Wallis or Chi-Square. II Major Injury=Abbreviated Injury Scale Score $\geq 3$. †Serious complications $=$ acute kidney injury, acute myocardial infarction, acute respiratory distress syndrome, cardiac arrest, cardiac failure, deep vein thrombosis, pulmonary embolism, pneumonia, sepsis, stroke and unplanned return to the operating room. ${ }^{1} \neq$ Includes Motorbike crash $§$ Includes violence, pedal cyclists, fire, sport related, other.

Table 3. Unadjusted and multivariate logistic regression analysis for trauma centre transport (direct/indirect) in major trauma patients who were transported by SJA-WA paramedics in the metropolitan area.

\begin{tabular}{|c|c|c|}
\hline & $\begin{array}{l}\text { Unadjusted } \\
\text { OR }(95 \% \mathrm{CI})\end{array}$ & $\begin{array}{c}\text { Adjusted } \\
\text { OR }(95 \% \mathrm{CI})\end{array}$ \\
\hline \multicolumn{3}{|l|}{ Age } \\
\hline 16-64 years & Reference & Reference \\
\hline $65-74$ years & $0.40(0.28-0.59)$ & $0.52(0.35-0.78)$ \\
\hline $75-84$ years & $0.31(0.23-0.43)$ & $0.48(0.33-0.71)$ \\
\hline$\geq 85$ years & $0.19(0.14-0.27)$ & $0.37(0.24-0.55)$ \\
\hline \multicolumn{3}{|l|}{ Mechanism of Injury } \\
\hline Other II & Reference & Reference \\
\hline Fall from Standing & $0.23(0.18-0.29)$ & $0.47(0.33-0.67)$ \\
\hline Other $\dagger$ & Reference & Reference \\
\hline Motor Vehicle Crash & $3.4(2.2-5.2)$ & $2.5(1.6-4.0)$ \\
\hline Other $\$$ & Reference & Reference \\
\hline Motor Bike Crash & $1.9(1.3-2.8)$ & $1.1(0.70-1.7)$ \\
\hline Other $\S$ & Reference & Reference \\
\hline Pedestrian & $2.7(1.5-5.0)$ & $2.5(1.3-5.0)$ \\
\hline \multicolumn{3}{|c|}{ Prehospital Glasgow Coma Scale } \\
\hline $13-15$ & Reference & Reference \\
\hline $9-12$ & $0.76(0.52-1.1)$ & $0.79(0.51-1.2)$ \\
\hline $6-8$ & $1.6(0.95-2.6)$ & $1.5(0.84-2.5)$ \\
\hline $3-5$ & $0.94(0.68-1.3)$ & $0.58(0.40-0.85)$ \\
\hline \multicolumn{3}{|l|}{ Injury Severity Score } \\
\hline $16-24$ & Reference & Reference \\
\hline$\geq 25$ & $0.92(0.73-1.6)$ & $0.92(0.70-1.2)$ \\
\hline \multicolumn{3}{|l|}{ Major Injury } \\
\hline Absent or AIS <3 & Reference & Reference \\
\hline Major Head Injury & $0.61(0.47-0.78)$ & $1.3(0.88-1.9)$ \\
\hline Absent or AIS <3 & Reference & Reference \\
\hline Major Chest Injury & $1.8(1.4-2.3)$ & $1.03(0.74-1.4)$ \\
\hline Absent or AIS $<3$ & Reference & Reference \\
\hline Major Abdominal Injury & $1.5(1.05-2.1)$ & $0.88(0.59-1.3)$ \\
\hline Absent or AIS <3 & Reference & Reference \\
\hline Major Extremity Injury & $2.0(1.4-2.8)$ & $1.4(0.96-2.1)$ \\
\hline \multicolumn{3}{|l|}{ Sex } \\
\hline Female & Reference & Reference \\
\hline Male & $2.0(1.6-2.5)$ & $1.4(1.1-1.8)$ \\
\hline
\end{tabular}


II Includes; Motor Vehicle Crash, Motorbike Crash, Pedestrian, Violence, Pedal Cyclist and Falls from Height, Fire, Sport-Related, Other. †Includes; Falls from Standing, Motorbike Crash, Pedestrian, Violence, Pedal Cyclist and Falls from Height, Fire, Sport-Related, Other. fIncludes; Falls from Standing, Motor Vehicle Crash, Pedestrian, Violence, Pedal Cyclist and Falls from Height, Fire, Sport-Related, Other. $\S$ Falls from Standing, Motor Vehicle Crash, Motorbike Crash, Pedestrian, Violence, Pedal Cyclist and Falls from Height, Fire, Sport-Related, Other

Table 4. Unadjusted and multivariate logistic regression analysis for in-hospital mortality using IPTW for major trauma patients age $\geq 65$ years of age who were transported by SJA-

WA paramedics in the metropolitan area.

\begin{tabular}{|lcc|}
\hline & Univariate & Adjusted OR \\
& OR & OR \\
& $(95 \%$ CI $)$ & \\
Transported to Trauma Centre & & Reference \\
Yes & Reference & $1.7(1.04-2.7)$ \\
No & $1.5(1.1-2.2)$ & \\
Age & & $1.06(1.03-1.1)$ \\
Age, years & $1.03(1.00-1.05)$ & \\
Injury Severity Score & & Reference \\
$16-24$ & Reference & $5.1(3.1-8.2)$ \\
$\geq 25$ & $7.2(4.7-10)$ & \\
Prehospital Systolic Blood Pressure & & Reference \\
SBP $\geq 90 \mathrm{mmHg}$ & Reference & $2.1(0.87-4.9)$ \\
SBP $<90 \mathrm{mmHg}$ & $3.7(2.1-6.6)$ & Reference \\
Prehospital Respiratory Rate & Reference & $5.9(2.8-12)$ \\
$10-29$ per min & $8.6(4.6-15)$ & Reference \\
$\leq 9$ or $>29$ per min & & $8.8(4.8-16)$ \\
Prehospital Glasgow Coma Scale & Reference & \\
$9-15$ & $16(9.3-30)$ & Reference \\
$3-8$ & & $1.8(0.80-4.0)$ \\
Major Head Injury & Reference & \\
AIS $<3$ & $2.10(1.2-3.6)$ & \\
AIS $\geq 3$ & & \\
& &
\end{tabular}

